\title{
ANTIOXIDANT EFFECT OF AQUEOUS EXTRACT OF MUCUNA PRURIENS (LINN) BY DPPH ASSAY-AN IN-VITRO STUDY
}

\author{
Akila Lakshmikandhan', Ramya Ravichandar ${ }^{2}$
}

${ }^{1}$ Associate Professor, Department of Pharmacology, Sree Balaji Medical College and Hospital, Chennai, Tamilnadu.

${ }_{2}^{2}$ Assistant Professor, Department of Pharmacology, Sree Balaji Medical College and Hospital, Chennai, Tamilnadu.

\begin{tabular}{l}
\hline ABSTRACT \\
BACKGROUND \\
In human, oxidative stress has been proposed in the pathogenesis of cardiovascular diseases, neurodegenerative disorders like \\
Alzheimer's disease, Parkinson's disease, amyotrophic lateral sclerosis, male and female infertility etc. \\
Objective- The present study was carried out to determine the antioxidant potential of Mucuna pruriens using DPPH assay.
\end{tabular}

\section{MATERIALS AND METHODS}

The seeds of M. pruriens were powdered and aqueous extract was prepared. DPPH (1,1-diphenyl-2-picrylhydrazyl) is a stable free radical. The unpaired electron delocalises over the molecule entirely and the molecules will not undergo dimerisation similar to majority of free radicals. This process resulted in formation of deep purple colour, characterised by an absorption band in ethanol solution. The absorbance of all samples was read at $517 \mathrm{~nm}$ using UV visible spectrophotometer. Antioxidant activity was calculated. Each step was carried out in triplicate and the average values were entered. The experimental results were expressed as mean \pm SD of three parallel measurements. IC50 (minimum inhibitory concentration) values were calculated graphically.

\section{RESULTS}

The DPPH scavenging activity of aqueous extract of Mucuna pruriens was recorded in terms of percentage inhibition. The results obtained were comparable to the standard BHT (Butylated Hydroxytoluene) in a dose dependent manner. Higher percentage scavenging indicates greater antioxidant potential; 1000 micrograms of AEMP shows greatest scavenging activity.

\section{CONCLUSION}

When there is an excessive generation of free radicals, it can result into oxidative stress which gets accumulated during the life span which has been contributed in long-term ailments, therefore it is vital to restrict oxidative injury to tissues and suppress progression of the disease by supplying antioxidants as nutraceuticals. The current study concludes that the aqueous extract of seeds of Mucuna pruriens demonstrated considerable antioxidant activity.

\section{KEYWORDS}

Mucuna Pruriens, Antioxidant Study, DPPH Assay.

HOW TO CITE THIS ARTICLE: Lakshmikandhan A, Ravichandar R. Antioxidant effect of aqueous extract of Mucuna pruriens (LINN) by DPPH assay- an in-vitro study. J. Evolution Med. Dent. Sci. 2018;7(08):1040-1043, DOI: 10.14260/jemds/2018/237

\section{BACKGROUND}

Parkinson's disease is a neurodegenerative disorder with a prevalence of 1 - 2 patients per 1000 people at any given time. The prevalence is rising with age and it affects $1 \%$ of the population in geriatric age group.[1] Exact aetiology of this disease is not known, though genetic and environmental factors including injury due to oxidative stress are known to play an important role in its pathogenesis.[2] Oxidative stress is defined as an interruption in the sense of balance between the synthesis of free radicals and antioxidant defence mechanisms resulting in the formation of toxic reactive oxygen species (ROS) like hydrogen peroxide, nitric oxide, organic hydroperoxides, superoxide and hydroxyl radicals. ${ }^{[3]}$

'Financial or Other Competing Interest': None.

Submission 11-01-2018, Peer Review 04-02-2018,

Acceptance 10-02-2018, Published 19-02-2018.

Corresponding Author:

Dr. Ramya Ravichandar,

Assistant Professor,

Department of Pharmacology,

Sree Balaji Medical College and Hospital,

Works Road, Chromepet, Chennai-600044,

Tamilnadu, India.

E-mail: dr.ramyaravichandar@gmail.com

DOI: $10.14260 /$ jemds $/ 2018 / 237$ pathogenesis of many diseases like cardiovascular diseases, eye disorders, joint disorders, neurological diseases like Alzheimer's disease, Parkinson's disease, amyotrophic lateral sclerosis, atherosclerosis, cancer, ageing, disease of the reproductive system including the male and female infertility etc.[4] World Health Organisation has stated that $60-80$ million married people have been affected with infertility.[5] That too incidence of male infertility is accounting for a minimum of 30 million men across the world.[6,7] We have numerous homeostatic processes to neutralise oxidative stress by the formation of antioxidants or by exogenous source like diet and/or nutraceuticals. ${ }^{[8]}$

Experiments have proven that many drugs have antioxidant property that may contribute to their pharmacological action in the management of the abovementioned conditions. Since these are chronic diseases, longterm adverse effects of the medications prescribed should be taken into consideration. In spite of recent advances in recombinant DNA technology and drug discovery methods, there is an immediate necessity of a hypothesis shift in methods to drug discovery. Natural products of Ayurveda offer a vast potential for novel phytomolecules with clinical activity. In India, Ayurveda is availed of by more than $70 \%$ of the population. $[9,10]$ In this current study, a popular ayurvedic compound whose vernacular name in Tamil is "Poonakali" 
with folkloric claim of anti-parkinsonian and male fertility enhancing effects was tested for its antioxidant effect.

The genus of "Poonakali" is Mucuna, which belongs to the family Fabaceae. The sub-family is Papilionaceae, which includes apparently 150 species of legumes. It is popularly known as velvet bean. It is named as "Poonakali" in Tamil as it resembles the foot of cat. This crop is well thought out as a viable source of dietary proteins. The protein concentration of this compound is as high as $35 \%{ }^{[11]}$

It has significant role in Ayurvedic medicine and this has been tested for several properties like anti-cancer, anticonvulsant, analgesic, oral anti-diabetic, drug used in male infertility, anti-parasitic, neuroprotective etc.[12] Its antivenom activities have been investigated by Guerranti $\mathrm{R}$ et al.[13] Jalalpure et al demonstrated the anti-helminthic activity of M. pruriens.[14] Misra and Wagner demonstrated the neuroprotective actions of Poonakali.[15] Hishika et al had shown its analgesic and anti-inflammatory activity.[16]

Understanding the pathophysiological process behind various activities of this seed extract is mandatory, which will enable us to explore other possible therapeutic uses of the same.

\section{Objective}

Therefore, the current study was carried out to determine the antioxidant potential of Mucuna pruriens using DPPH assay, which is a popular method to find out antioxidant status of a compound.[17]

\section{MATERIALS AND METHODS Study Design}

It is an in-vitro study to determine the free radical scavenging activity of Mucuna pruriens by DPPH assay in comparison with a standard compound (BHT- Butylated Hydroxytoluene) using spectrophotometer.

\section{Drug Source}

The seeds of M. pruriens were collected from the country drug store at market place in Adambakkam, Chennai, Tamilnadu and a taxonomist authenticated it. The seeds were powdered in home grinder. A sample of the voucher specimen has been kept in the department library for further references (Access number: 201/SBMC/001). $80^{\circ} \mathrm{C}$ of distilled water was added in dried powder of seeds and was stirred gently. This was allowed to cool and filtered. Reduced pressure was used to concentrate the filtrate. The extract was refrigerated under 2 - 8 degree Celsius until further use.[18] AEMP is used to abbreviate Aqueous Extract of Mucuna pruriens from here onwards.

\section{DPPH Assay}

Free radical scavenging ability of the Poonakali seed extract was determined in accordance to the method of Blois MS. DPPH (1,1-diphenyl-2-picrylhydrazyl) is a free radical, which is stable. The unpaired electron delocalises over the molecule entirely, and the molecules will not undergo dimerisation similar to majority of free radicals. This process resulted in formation of deep purple colour, characterised by an absorption band in ethanol solution centred at about $520 \mathrm{~nm}$. When a solution of DPPH is mixed with that of a substance that can provide a hydrogen atom, this will result in the production of a reduced product and the violet colour is not formed now.[19,20] If we represent the DPPH radical by Z• and the donor molecule by $\mathrm{AH}$, the primary reaction is $\mathrm{Z} \bullet+\mathrm{AH}=$ $\mathrm{ZH}+\mathrm{A} \bullet$ where $\mathrm{ZH}$ is the reduced form and $\mathrm{A} \bullet$ is free radical produced in this initial step. This free radical formed will then go through further reactions which control the entire stoichiometry, which means the number of molecules of DPPH reduced (decolourised) divided by one molecule of the reductant.

\section{Chemicals}

1, 1-diphenyl-2-picrylhydrazyl (DPPH), Dimethyl sulfoxide (DMSO), BHT (Butylated Hydroxytoluene) (standard)- 1.6 $\mathrm{mg} / \mathrm{mL}$ in methanol and samples desired concentration from $1 \mathrm{mg} / \mathrm{mL}-\max$ of $5 \mathrm{mg} / \mathrm{mL}$ (in/DMSO) were used in this study.

\section{Procedure}

DPPH free radical scavenging assay is the widely accepted method to find out the antioxidant efficacy of an extract. Merits of DPPH assay are being quick, easy and cheap. In this study, antioxidant efficacy of AEMP and BHT (Butylated Hydroxytoluene)- a standard and well proven antioxidant chemical were compared.

The seed extract was serially diluted from $31.25 \mu \mathrm{g} / \mathrm{mL}$ to $1000 \mu \mathrm{g} / \mathrm{mL}$ and the same concentrations of standard were also taken. $3.7 \mathrm{~mL}$ of absolute methanol was liquored in all test tubes containing extract as well as blank. $100 \mu \mathrm{L}$ of BHT was added to tube marked as standard and $100 \mu \mathrm{L}$ of respective samples to all other tubes marked as tests. DPPH reagent measuring 200 microlitre was added to all the test tubes including blank. At room temperature, all test tubes were incubated in dark condition for half an hour. The absorbance of all samples was read at $517 \mathrm{~nm}$ using UV visible spectrophotometer.

\section{Calculation}

The percentage of antioxidant activity of M. pruriens was calculated using the following formula.

$\%$ Antioxidant activity $=($ Absorbance at blank $)-($ Absorbance at test $) \times 100$ (Absorbance at blank)

\section{Statistical Analysis}

Each step was carried out in triplicate $(n=3)$ and the average values were entered in Table 1 . The experimental results were expressed as mean \pm SD of three parallel measurements. Figure-1 shows graphical representation of the same and IC50 (minimum inhibitory concentration) values were determined.

This was done to interpret the concentration required to inhibit the $50 \%$ of free radicals.

\section{RESULTS}

Mucuna pruriens produced a yield of $5.2 \mathrm{~g}$ of extract per $10 \mathrm{~g}$ of seed powder. In this current study, aqueous extract of Mucuna pruriens was tested for its activity against free radicals. In this current investigation, the widely accepted assay namely DPPH was employed for the determination of antioxidant activity of Poonakali seeds. The DPPH scavenging activity was recorded in terms of percentage inhibition. The results thus obtained were comparable to BHT (Butylated Hydroxytoluene), which was the standard. Higher Percentage 
scavenging indicates greater antioxidant potential. 1000 micrograms of AEMP shows greatest scavenging activity.[21]

An inspection of Table- 1 and Figure- 1 showed that the total antioxidant activity, estimated by DPPH method, ranged from 31.25 to 1000 micrograms per $\mathrm{mL}(\mathrm{mcg} / \mathrm{mL})$. Higher percentage scavenging indicates greater antioxidant potential. Thus, these observations confirm once again that some native medicinal plants commonly used in our country are competent resources of potential antioxidants.

\begin{tabular}{|c|c|c|c|c|c|c|}
\hline \multirow[b]{2}{*}{ Sl. No } & \multirow{2}{*}{$\begin{array}{c}\text { Concentration } \\
(\mu \mathrm{g} / \mathrm{mL})\end{array}$} & \multirow[b]{2}{*}{ Log Conc. } & \multicolumn{2}{|c|}{ Aqueous Extract of M. pruriens } & \multicolumn{2}{|c|}{ Standard (BHT) } \\
\hline & & & $\begin{array}{l}\text { \% Scavenging } \\
(\text { Mean } \pm \text { SEM) }\end{array}$ & $\mathrm{IC}_{50}(\mu \mathrm{g} / \mathrm{mL})$ & $\begin{array}{l}\text { \% Scavenging } \\
(\text { Mean } \pm \text { SEM) }\end{array}$ & $\mathrm{IC}_{50}(\mu \mathrm{g} / \mathrm{mL})$ \\
\hline 1 & 31.25 & 1.49485 & $29.06 \pm 0.370$ & \multirow{5}{*}{$277.37 \pm 0.22$} & $28.81 \pm 0.160$ & \multirow{5}{*}{$71.30 \pm 0.12$} \\
\hline 2 & 62.5 & 1.79588 & $38.74 \pm 0.130$ & & $49.53 \pm 0.030$ & \\
\hline 3 & 125 & 2.09691 & $44.35 \pm 0.375$ & & $53.87 \pm 0.015$ & \\
\hline 4 & 250 & 2.39794 & $48.03 \pm 0.050$ & & $61.65 \pm 0.410$ & \\
\hline 5 & 500 & 2.69897 & $51.87 \pm 0.210$ & & $76.48 \pm 0.005$ & \\
\hline 6 & 1000 & 3.01254 & $60.61 \pm 1.10$ & & $97.00 \pm 0.25$ & \\
\hline \multicolumn{7}{|c|}{ Table 1. DPPH Scavenging activity of Aqueous Extract of M. pruriens } \\
\hline
\end{tabular}

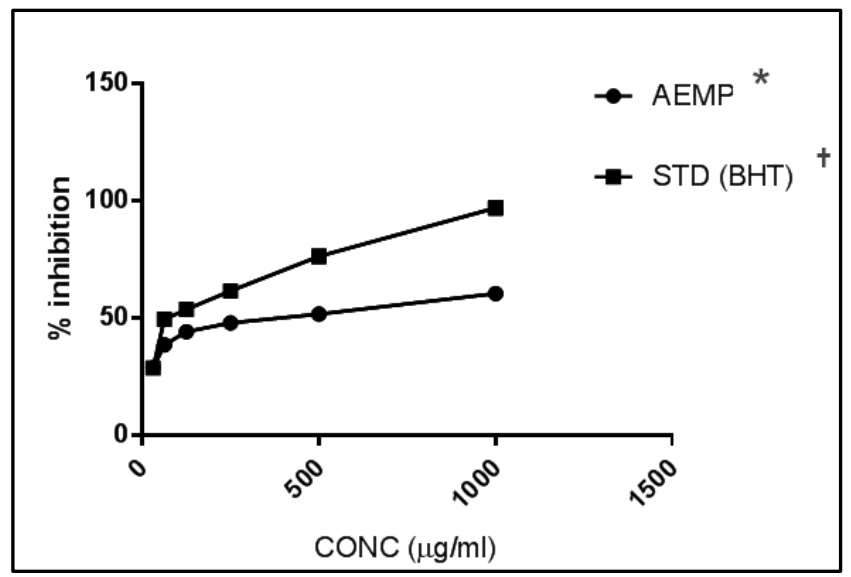

Figure 1. Determination of IC50 Value of Aqueous Extract of M. pruriens by DPPH Scavenging Activity

* Aqueous extract of Mucuna pruriens.

† Butylated Hydroxytoluene.

\section{DISCUSSION}

The average lifespan of the world population is rising. By the year 2025, 29\% of the world population will be of geriatric population. This will result in a rise in the number of elderly individuals acquiring degenerative long-term diseases. This is going to add a great burden financially on health care services. The equilibrium between reactive free radicals and antioxidants is vital in regulating an individual's health and disease. Oxidative stress induced by free radicals is regulated by a person's in vivo antioxidant systems. When there is an excessive generation of free radicals, it can result into oxidative stress which gets accumulated during the lifespan and has been contributed in long-term ailments.[22]

Therefore, it is vital to restrict oxidative injury to tissues and therefore suppress progression of the disease by supplying antioxidants as nutraceuticals. ${ }^{[23,24]}$ The concept of getting information to support reverse pharmacology is certainly valuable to human health based on the molecular mechanism of action of the compound.

\section{CONCLUSION}

The current study concludes that the aqueous extract of seeds of Mucuna pruriens demonstrated considerable antioxidant activity. Similar to Mucuna pruriens, many of the flora remain less popular. Various attempts should be taken forward to experiment and document the effects of these biological compounds.

\section{Future Prospects}

Many more investigations regarding the extraction and localisation of biologically active components of Mucuna pruriens would assist us in determining its potency.

\section{ACKNOWLEDGEMENTS}

We thankfully acknowledge the management, dean, vice principal and HOD, Pharmacology for their motivation in carrying out research projects.

\section{REFERENCES}

[1] Tysnes OB, Storstein A. Epidemiology of Parkinson's disease. J Neural Transm (Vienna) 2017;124(8):901-5.

[2] Schapira AH. Etiology of Parkinson's disease. Neurology 2006;66(10 Suppl 4):S10-23.

[3] Betteridge DJ. What is oxidative stress? Metabolism 2000;49(2 Suppl 1):1:3-8.

[4] Rahman T, Hosen I, Islam MMT, et al. Oxidative stress and human health. Advances in Bioscience and Biotechnology 2012;(3):997-1019.

[5] Infecundity, infertility, and childlessness in developing countries. DHS Comparative Reports No 9. Calverton, Maryland, USA: ORC Macro and the World Health Organization 2004.

[6] Agarwal A, Mulgund A, Hamada A, et al. A unique view on male infertility around the globe. Reprod Biol Endocrinol 2015;13:37.

[7] Kumar N, Singh AK. Trends of male factor infertility, an important cause of infertility: a review of literature. J Hum Reprod Sci 2015;8(4):191-6.

[8] Sharma N. Free radicals, antioxidants and disease. Biol Med 2014;6(3):1-6.

[9] Vaidya ADB. Reverse pharmacology-a paradigm shift for drug discovery and development. Current Research in Drug Discovery 2014;1(2):39-44.

[10] Lampariello LR, Cortelazzo A, Guerranti R, et al. The magic velvet bean of Mucuna pruriens. J Tradit Complement Med 2012;2(4):331-9.

[11] Janardhanan K, Gurumoorthi P, Pugalenthi M. Nutritional potential of five accessions of a South Indian tribal pulse, Mucuna pruriens var. utilis. Part I. The effect of processing methods on the contents of L- 
Dopa phytic acid, and oligosaccharides. Tropical and Subtropical Agroecosystems 2003;1:141-52.

[12] Sathiyanarayanan L, Arulmozhi S. Mucuna pruriens Linn. A comprehensive review. Pharmacognosy Rev 2007;1(1):157-62.

[13] Guerranti R, Ogueli IG, Bertocci E, et al. Proteomic analysis of the pathophysiological process involved in the antisnake venom effect of Mucuna pruriens extract. Proteomics 2008;8(2):402-12.

[14] Jalalpure SS, Alagawadi KR, Mahajanashetti CS. In vitro anthelmintic property of various seed oils against Pheritima posthuma. Indian Pharm Sci 2007;69(1):158-60.

[15] Misra L, Wagner H. Extraction of bioactive principles from Mucuna pruriens seeds. Indian J Biochem Biophys 2007;44(1):56-60.

[16] Hishika R, Shastry S, Shinde S, et al. Preliminary phytochemical and anti-inflammatory activity of seeds of Mucuna pruriens. Indian J pharmacol 1981;13(1):97-8.

[17] Sindhuja M, Muthiah NS, Rajeswari R. Comparative efficacy of Canagliflozin versus Empagliflozin on oxidative stress - in-vitro method. Int J Pharma Bio Sci 2017;8(4):232-6.
[18] Akila L, Rani RJ, Kiran B, et al. invitro antioxidant and free radical scavenging properties of flower extract of cassia auriculata, Linn (caesalpiniaceae). International Journal of Phytopharmacology 2016;7(4):209-13.

[19] Olugbami JO, Gbadegesin MA, Odunola OA. In vitro free radical scavenging and antioxidant properties of ethanol extract of Terminalia glaucescens. Pharmacognosy Research 2015;7(1):49-56.

[20] Blois MS. Antioxidant determinations by the use of a stable free radical. Nature 1958;181:1199-200.

[21] Rajurkar NS, Hande SM. Estimation of phytochemical content and antioxidant activity of some selected traditional Indian medicinal plants. Indian J Pharm Sci 2011;73(2):146-51.

[22] Rahman K. Studies on free radicals, antioxidants, and co-factors. Clin Interv Aging 2007;2(2):219-36.

[23] Devi VS, Ushanandhini R, Kumar KA, et al. Antioxidant activity of Cassia auriculata Linn flowers. Pharmacologyonline 2011;2:490-8.

[24] Ajanal M, Nayak S, Prasad BS, et al. Adverse drug reaction and concepts of drug safety in Ayurveda: an overview. J Young Pharm 2013;5(4):116-20. 